\title{
A precarização do trabalho docente e o adoecimento mental no contexto neoliberal
}

\author{
Juliana da Silva Moura \\ Universidade Estadual do Sudoeste da Bahia - UESB, Brasil \\ Júlia Cecília de Oliveira Alves Ribeiro \\ Universidade Estadual do Sudoeste da Bahia - UESB, Brasil \\ Abília Ana de Castro Neta \\ Universidade Estadual do Sudoeste da Bahia - UESB, Brasil \\ Claudio Pinto Nunes \\ Universidade Estadual do Sudoeste da Bahia - UESB, Brasil
}

\section{RESUMO}

Esse estudo objetiva analisar as condições do trabalho docente, sua precarização e suas implicações para a saúde mental do professor. As condições de trabalho são indispensáveis para que o docente cumpra sua função de forma a favorecer a aprendizagem dos educandos e, ao mesmo tempo, promover seu desenvolvimento profissional. No entanto, as investidas neoliberais têm provocado mudanças nas formas de produção alterando as configurações do trabalho. No âmbito educacional, o neoliberalismo inseriu-se através de reformas que contribuíram para promover a precarização do trabalho docente. Este trabalho é fruto de um levantamento bibliográfico, ancorado nos pressupostos do materialismo dialético. Os estudos evidenciam a importância de se romper com a situação de precarização do trabalho docente. Para tanto, torna-se necessário que a realidade atual seja transformada em prol da classe trabalhadora e a partir dela. Além disso, este texto destaca a importância da mobilização dos profissionais da área junto a sindicatos e outros setores da sociedade, no sentido de exigir das autoridades competentes o cumprimento da legislação que ampara a valorização docente e preconiza adequadas condições de trabalho para este profissional. Em síntese, registra-se que muitas mudanças com relação às condições de trabalho e de saúde docentes precisam ser amplamente discutidas e efetivadas.

PALAVRAS-CHAVE: Trabalho docente. Precarização. Adoecimento mental.

\section{THE PRECARIOUSNESS OF TEACHING WORK AND THE ILLNESS MENTAL IN THE NEOLIBERAL CONTEXT}

\begin{abstract}
This study aims to analyze the conditions of teaching work, its precariousness and its implications for the mental health of the teacher. The conditions of teaching work the conditions of teaching work are essential for the teacher to fulfill his / her function in a way that favors the students' learning and, at the same time, their professional progress. The neoliberal onslaughts have caused changes in the forms of production by changing the job settings. In the educational sphere, neoliberalism was inserted through reforms that contributed to promote the
\end{abstract}


precariousness of teaching work. This work is the fruit of a bibliographical research, anchored in the assumptions of dialectical materialism. The studies show the importance of breaking with the precarious situation of the teaching work. Therefore, it is necessary that the current reality be transformed in favor of the working class and from it. In addition, this text highlights the importance of mobilizing professionals from the area as unions and other sectors of society, in order to demand from the competent authorities compliance with the legislation that protects the teacher appreciation and advocates adequate working conditions for this professional. In summary, it is recorded that many changes regarding working conditions and teacher health need to be widely discussed and effected.

KEYWORDS: Teaching work. Precariousness. Mental Illness.

\section{LA PRECARIZACIÓN DEL TRABAJO DOCENTE Y EL ADOECIMIENTO MENTAL EN EL CONTEXTO NEOLIBERAL}

\section{RESUMEN}

Este estudio tiene como objetivo analizar las condiciones del trabajo docente, su precarización y sus implicaciones para la salud mental del profesor. Las condiciones de trabajo son indispensables para que el docente cumpla su función para favorecer el aprendizaje de los educandos y al mismo tiempo promover su desarrollo profesional. Sin embargo, las inversiones neoliberales han provocado cambios en las formas de producción cambiando la configuración del trabajo. En el ámbito educativo, el neoliberalismo se insertó a través de reformas que contribuyeron a promover la precarización del trabajo docente. Este trabajo es fruto de una investigación bibliográfica, anclada en los presupuestos del materialismo dialéctico. Los estudios evidencian la importancia de romperse con la situación de precarización del trabajo docente. Para ello, se hace necesario que la realidad actual sea transformada en favor de la clase obrera y a partir de ella. Además, este texto destaca la importancia de la movilización de los profesionales del área junto a sindicatos y otros sectores de la sociedad, en el sentido de exigir de las autoridades competentes el cumplimiento de la legislación que ampara la valorización docente y preconiza adecuadas condiciones de trabajo para este profesional. En síntesis, se registra que muchos cambios con relación a las condiciones de trabajo y de salud docentes requieren ser ampliamente discutidas y efectivizadas.

PALABRAS CLAVE: Trabajo docente. Precarización. Adoecimiento mental.

\section{INTRODUÇÃO}

As mudanças nos processos de produção capitalista são constantes e atravessam fases cíclicas que alternam entre declínio e ascensão do sistema. No bojo dessas mudanças, vimos emergir a ideologia neoliberal que traz a prerrogativa do Estado-mínimo, ou seja, a baixa atuação do poder público para as demandas sociais, controle dos gastos públicos, desregulamentação dos direitos trabalhistas, reformas fiscais e investimentos para tornar a economia forte e promover o equilíbrio monetário. Sobre o período neoliberal, Gomes et al. (2012) informam:

O esgotamento do padrão de acumulação fordista/taylorista induziu o capital a buscar estratégias de recuperação das taxas de lucro através das propostas 
neoliberais, que enxergavam no Estado, e em suas políticas sociais, como o grande vilão da economia. Os intelectuais comprometidos com as bandeiras do neoliberalismo declaravam que as despesas do Estado com políticas públicas e o poder dos sindicatos destruíam os níveis necessários de lucro das empresas (GOMES et al., 2012, p. 274).

Partindo dessas premissas, os reformadores educacionais, especialmente na década de 1990, propuseram mudanças no sistema educacional orientadas pelos mecanismos internacionais, visando a privatização direta ou indireta do serviço público, a diminuição dos gastos com educação e demais setores sociais, além do gerenciamento e controle sobre a ação docente. Tais medidas afetaram seriamente as condições de trabalho do professor, que há longa data já não eram consideradas satisfatórias.

É nesse contexto que buscamos refletir sobre a importância do trabalho docente e as transformações pelas quais tem passado, desencadeando um processo de precarização e consequentemente implicações para a saúde desse profissional.

Destacamos que as condições de trabalho são indispensáveis para que o docente cumpra sua função de forma a favorecer a aprendizagem dos educandos e, ao mesmo tempo, promover seu desenvolvimento profissional.

Barros (2013) define "condições de trabalho docente" como um conjunto de recursos que possibilita uma efetiva realização do trabalho e que envolve a infraestrutura da instituição, os materiais disponíveis, os serviços de apoio, ou seja, as circunstâncias indispensáveis para que a atividade de trabalho se realize e se desenvolva concretamente, para que o trabalho seja materializado efetivamente.

Ao investigar a literatura norte-americana, Pereira Junior (2017, p. 81-82) preconiza que:

[...] o estudo The Workplace Matters: teacher quality, retention, and effectiveness, desenvolvido por Susan Moore Johnson da Universidade de Harvard, considerou condições de trabalho uma necessidade para o professor desenvolver as atividades de ensino. Caso as condições fossem deficientes ou precárias, nem mesmo os docentes dotados dos conhecimentos e das habilidades necessárias para lecionar seriam efetivos ao ensinar.

Pereira Junior (2017), inspirado no estudo desenvolvido por Susan Johnson, aponta que a precarização e/ou a deficiência das condições de trabalho docente inviabiliza a efetivação do ensino de qualidade. Essa precarização, ocasionada e/ou intensificada pelo desenvolvimento do ideário neoliberal, também afeta, notadamente, o quadro de saúde dos professores. Este dado é comprovado por inúmeras pesquisas, dentre elas, a de Gasparine, Barreto e Assunção (2005). Estes autores apontam que $84 \%$ dos servidores que se afastaram do trabalho entre os anos de 2001 a 2002 eram da categoria de professores. 
A metodologia adotada para o desenvolvimento desse trabalho baseia-se em um levantamento bibliográfico que busca uma aproximação com os pressupostos do materialismo histórico dialético. O levantamento bibliográfico justifica-se por ser um importante instrumento das investigações acadêmicas e "revela explicitamente o universo de contribuições científicas de autores sobre um tema específico" (SANTOS; CANDELORO, 2006, p. 43). Já as pesquisas crítico-dialéticas, que têm origem no materialismo, justificam-se neste artigo, por sua intencionalidade e pelo fato de que:

[...] sua postura marcadamente crítica expressa a pretensão de desvendar, mais que o "conflito das interpretações", o conflito dos interesses. Essas pesquisas manifestam um "interesse transformador" das situações ou fenômenos estudados, resguardando sua dimensão sempre histórica e desvendando suas possibilidades de mudanças (GAMBOA, 2010. p. 107-108).

O materialismo histórico dialético busca conhecer as relações concretas e efetivas dos fenômenos, em termos de categorias básicas do marxismo: contradição, totalidade, classes, luta de classes e trabalho. De acordo com Cheptulin (2004), o método dialético analisa as formas gerais do ser histórico, bem como os aspectos e os vínculos gerais da realidade e as leis que refletem essa realidade na consciência dos homens. O materialismo histórico dialético possibilita ir do fato empírico (fenômeno) para o conceito e, num movimento lógico, o desvelamento das contradições essenciais do fenômeno, se fixa na essência, no mundo real, no conceito, na consciência real, na teoria e ciência (KOSIK, 1997).

A partir desta investigação, esperamos contribuir para a ampliação das discussões acerca da precarização do trabalho e do adoecimento docente e suscitar o desenvolvimento de novos estudos que possibilitem "conduzir o embate com alguma chance de reverter a situação, senão imediatamente, acumulando energia para o momento em que a correlação de forças se tornar mais favorável” (SAVIANI, 2003, p. 237).

\section{O PERÍODO NEOLIBERAL E SUAS REPERCUSSÕES NA EDUCAÇÃo E NO TRABALHO DOCENTE}

Abordar o trabalho docente no momento atual requer uma reflexão acerca das condições e relações de trabalho desenvolvidas nas últimas décadas decorrentes da reestruturação do capitalismo. Uma das prerrogativas do capital é o acúmulo de riquezas tendo como contraponto a exploração do trabalho e a produção de um maior abismo entre a classe dominante burguesa e a classe trabalhadora. No mundo contemporâneo, as relações de trabalho já não são as mesmas observadas ao longo do século XIX; a classe trabalhadora ampliou-se e diversificou-se, não estando presa apenas às atividades industriais, dadas as relações capitalistas de produção que 
atravessam um processo de transformações históricas contínuas para atender ao seu fim. Antunes (1999) desenvolve a expressão de "classe-que-vive-do-trabalho" para dar uma validade contemporânea ao conceito de classe trabalhadora.

Portanto, ao contrário dos autores que defendem o fim das classes sociais, o fim da classe trabalhadora, ou até mesmo o fim do trabalho, a expressão classe-que-vive-do-trabalho pretende dar contemporaneidade e amplitude ao ser social que trabalha, à classe trabalhadora hoje, aprender sua efetividade, sua processualidade e concretude (ANTUNES, 1999, p. 101).

A classe-que-vive-do-trabalho, segundo o autor, abrange tanto trabalhadores que formam o núcleo do trabalho produtivo, como os trabalhadores improdutivos, que são os que vendem sua força de trabalho na prestação de serviços, quer públicos ou privados. A noção ampliada de classe trabalhadora proposta por Antunes (1999) consegue englobar trabalhadores das mais variadas categorias, como os docentes e, ao mesmo tempo, expõe as condições de precarização e intensificação do trabalho originadas no auge do desenvolvimento tecnológico que promove uma maior produção com menores custos. Em contrapartida, gera uma quantidade absurda de trabalhadores que se submetem a qualquer tipo de condição de trabalho para garantir sua sobrevivência e não figurar nos índices de desemprego.

Marx e Engels (1998), no Manifesto do Partido Comunista, expõem a essência do capitalismo, sua tendência às mudanças e consequências aos trabalhadores:

\begin{abstract}
A burguesia não pode existir sem revolucionar permanentemente os instrumentos de produção - por conseguinte, as relações de produção e, com isso, todas as relações sociais. A conservação inalterada do antigo modo de produção era, pelo contrário, a condição primeira da existência de todas as anteriores classes industriais. A contínua subversão da produção e, com isso, todas as relações sociais, a permanente incerteza e a constante agitação distinguem a época da burguesia de todas as épocas precedentes. Dissolvemse todas as relações sociais antigas e cristalizadas, com o seu cortejo de representações e concepções secularmente veneradas; todas as relações que as substituem envelhecem antes de se consolidarem. Tudo o que era sólido e estável se dissolve no ar, tudo o que era sagrado é profanado e os homens são enfim obrigados a encarar, sem ilusões, a sua posição social e as suas relações recíprocas (MARX; ENGELS, 1998, p. 8).
\end{abstract}

Ao escrever sobre a dissolução de todas as relações sociais antigas, os autores complementam que os homens devem encarar sua posição social, pois o ideal burguês fará tudo que for possível para a manutenção da ordem social que reforça a submissão de todo trabalhador à lógica do capitalismo.

Mais recentemente, a partir da década de 1950, assistimos a uma fase promissora para o capitalismo, marcada pelo fortalecimento do Estado de bem-estar social, que tinha como premissa a intervenção do Estado na economia, na promoção dos direitos sociais e no combate ao desemprego. O rápido crescimento econômico dessa fase que se seguiu ao pós-guerra 
começou a declinar no início dos anos 1970, dando espaço para mais uma investida capitalista que se segue até os dias de hoje.

Nesse cenário, os Estados Nacionais, fortalecidos na defesa da ordem burguesa, com a privatização das empresas estatais e com promoção de políticas de defesa da liberdade econômica, fortalecem a defesa do mercado como agente regulador das relações sociais. Assim sendo, o discurso conservador neoliberal equipara tudo o que é estatal com a ineficiência, a corrupção e o desperdício, enquanto que a "iniciativa privada" surge sublimada como a esfera da competência administrativa, da probidade e da austeridade (GOMES et al., 2012, p. 275).

De acordo com as palavras dos autores, o discurso dos capitalistas passou a culpar o Governo pelos problemas da sociedade, transmitindo uma mensagem de incapacidade administrativa e de responsabilização pelo declínio da economia e pela crise social, defendendo a entrada da iniciativa privada, muito eficiente, na visão deles, na administração pública. No Brasil, a investida neoliberal foi ainda mais forte a partir da década de 1990. Sobre este período, Maués (2010, p.2) afirma:

$\mathrm{Na}$ atual crise, diferentemente daquela que marcou as décadas de 1970 e 1980, não se culpou o Estado, mas se buscou nele o socorro necessário para dela sair. Os Estados injetaram muitos bilhões/trilhões para ajudar os capitalistas a se recuperarem. Os recursos públicos, que poderiam ser aplicados em políticas sociais, foram desviados para os banqueiros e industriais. Com isso há uma diminuição dos recursos, que são finitos, para atender aquilo que deve ser o real papel de um governo, o bem-estar social.

Esta reestruturação produtiva presente na administração brasileira da década de 1990 foi responsável por uma série de reformas neoliberais, inclusive na área educacional, pautadas nas recomendações de órgãos internacionais como o Banco Mundial, redução no orçamento para fins sociais, políticas de controle do déficit fiscal, não cumprimento de metas propostas nos documentos oficiais. Nesse contexto, as condições de trabalho docente também foram afetadas, como conclui Saviani (2008, p.448-449):

Nessa nova conjuntura, como se situa o professor? O quarto ato de seu drama reveste-se de algumas particularidades. Continua-se pedindo que ele seja eficiente e produtivo, mas agora ele não necessita seguir um planejamento rígido; não precisa pautar sua ação por objetivos predefinidos, seguindo a regras preestabelecidas. Como ocorre com os trabalhadores de modo geral, também os professores são instados a se aperfeiçoarem continuamente num eterno processo de aprender a aprender. Acena-se, então, com cursos de atualização ou reciclagem, dos mais variados tipos, referidos a aspectos particulares e fragmentados da atividade docente, todos eles aludindo a questões práticas do cotidiano. $\mathrm{O}$ mercado e seus porta-vozes governamentais parecem querer um professor ágil, leve, flexível; que, a partir de uma formação inicial ligeira, de curta duração e a baixo custo, prosseguiria sua qualificação no exercício docente lançando mão da reflexão sobre sua própria prática, apoiado eventualmente por cursos rápidos, ditos também "oficinas"; essas recorrendo aos meios informáticos, transmitiriam em dose 
homeopáticas, as habilidades que o tornariam competente nas pedagogias da "inclusão excludente", do "aprender a aprender" e da "qualidade total". Mas o exercício dessas competências não se limitaria à atividade docente propriamente dita. Pede-se aos professores que, no espírito da "qualidade total", não apenas ministrem aulas, mas também participem da elaboração do projeto pedagógico das escolas; da vida da comunidade, animando-a e respondendo às suas demandas; da gestão da escola e suprindo suas dificuldades específicas.

Ao analisar esta afirmação, é possível inferir que, a partir de tais reformas, os professores tiveram seu trabalho ampliado sem que isso significasse melhorias ou maior valorização para sua carreira. A partir de então, o Governo, além de sobrecarregar os professores com tarefas que superam seu compromisso em sala de aula, passou a incorporar diversas avaliações internas e externas que culminaram numa maior exigência e num maior controle de seu trabalho, que junto com a demanda, salários baixos e condições de trabalho impróprias desencadearam em larga escala a precarização do trabalho docente.

A seguir discutiremos a importância do trabalho do professor para a formação humana, bem como os processos de precarização pelos quais tem passado.

\section{O TRABALHO DOCENTE: CONTRADITÓRIA PRECARIZAÇÃO E IMPLICAÇÕES PARA A SAÚDE DO PROFESSOR}

O trabalho docente constitui-se um pilar para a formação omnilateral dos sujeitos. Os professores são responsáveis pela mediação do saber historicamente produzido pela humanidade. $\mathrm{O}$ trabalho docente tem como finalidade, entre outros aspectos, contribuir para a construção e a transformação dos sujeitos em direção à humanização e à socialização (MARTINS; DUARTE, 2010). Afirmamos, ainda, que a atuação dos professores é responsável por contribuir no desenvolvimento do senso crítico, da análise da realidade, da capacidade de perceber os fatores que interferem na construção do ser, bem como na preparação dos discentes para uma atuação autônoma no mundo e para sua entrada no mundo do trabalho. Nas palavras de Tardif e Lessard (2014, p.198), as atribuições docentes na escola "visam a preparar os jovens para a vida adulta, formando-os para os saberes e as habilidades necessárias à vida profissional, educando-os moralmente em função das orientações básicas do status de adulto".

O professor desenvolve diversos trabalhos em sala de aula e uma série de atividades extraclasse. Entre elas, destacamos: desenvolvimento de projetos com a comunidade, alunos e suas famílias; reuniões e interação entre os colegas de profissão e a direção da escola; planejamento e correção de aulas, trabalho e provas; realização de relatórios, etc. Suas 
demandas são diversas e a sua jornada de trabalho acontece dentro e fora da instituição escolar (OLIVEIRA, 2004). Contribuindo nessa perspectiva, Gomes et al. (2012) salientam:

Pensar a educação em sua totalidade significa compreender que o trabalho diário do professor não se resume apenas à prática pedagógica, mas requer também fundamentação teórica para o desenvolvimento de seu trabalho, estrutura física das escolas, organização do tempo e do espaço, jornada de trabalho adequada, salários compatíveis, plano de carreira, entre outros. Sem essas condições materiais, a tendência é que os professores não se reconheçam no produto de seu trabalho. Por isso, essa precarização é sentida nas nossas Instituições Educacionais, sejam básica ou superior (GOMES et al., 2012, p. 280).

Frente a isso, é importante sinalizar que a docência é um trabalho que envolve aspectos físicos e mentais do profissional. Essa configuração do trabalho docente exige dele uma carga laboral excessiva que ultrapassa o seu tempo de trabalho remunerado. Tal fato tornou-se comum após as mudanças que vêm acontecendo nas últimas décadas, como afirmamos anteriormente, decorrentes das reformas de ordem neoliberal que têm sido adotadas no Brasil.

Com relação às reformas educacionais, Mancebo et al. (2006, p. 1) salientam que são "[...] reordenações a que os sistemas educacionais foram submetidos a partir da profunda redefinição do papel do Estado na relação com a educação, tendo conduzido, dentre outros aspectos, a processos variados de privatização".

Originadas e respaldadas nas orientações de mecanismos internacionais, como o Banco Mundial, a Organização de Cooperação e de Desenvolvimento Econômico (OCDE), o Banco Internacional para Reconstrução e Desenvolvimento (BIRD), dentre outros, essas reformas foram concretizadas mediante a parceria entre o Estado e uma rede de empresários que se apresentaram como entidades preocupadas com a educação e viam no modelo empresarial a saída para tornar as escolas mais eficientes. No entanto, Montoro (2014) nos alerta que o objetivo dessas organizações empresariais é subordinar o conjunto da sociedade aos ditames ideológicos e econômicos do capital e das nações imperialistas (MONTORO, 2014).

Nesta perspectiva, Peroni, Caetano e Lima (2017, p. 418) esclarecem que:

As reformas na educação brasileira fazem parte de um projeto que não dialoga com os principais envolvidos nas propostas em curso - professores, alunos, comunidade escolar - e apresenta-se como uma afronta à democracia. Os principais envolvidos no processo de construção de uma base nacional comum curricular e do novo ensino médio se apresentam como sujeitos individuais ou coletivos através de instituições públicas e privadas que atuam no setor educacional, institutos e fundações ligadas a grandes empresas nacionais e internacionais, bem como, instituições financeiras ligadas ao mercado de capitais, visando construir um projeto hegemônico de educação e de sociedade. 
Esses "reformadores empresariais da educação"1, juntamente com o Estado, pretendem levar para a educação pública alguns aspectos da organização do trabalho na rede privada. Através da padronização e automação das atividades, da imposição do material didático e métodos de ensino, eles estão direcionando e monitorando o papel do professor dentro das instituições escolares (FREITAS, 2014).

Diante de tal investida, o trabalho docente, que possui uma importância incontestável na melhoria da educação, na evolução humana dos educandos e no progresso das sociedades, atravessa, contraditoriamente, uma fase de precarização e desvalorização, seguidos pela destruição moral dos professores, que são culpabilizados pelo fracasso na educação, sofrem segregação econômica e assistem à destruição do sistema público de ensino (FREITAS, 2014).

Nesse contexto, o professor vê seu trabalho assumindo novos contornos, nova conjuntura e novas condições que, em vez de promoverem o seu desenvolvimento profissional, provocam uma sobrecarga de trabalho e cobranças que subtraem suas energias e conduzem a um estado de alienação e, não raro, a casos de adoecimentos.

Sobre as recentes transformações do trabalho docente, Abonízio (2012) afirma que:

[...] as condições de trabalho que essa categoria profissional está submetida têm sofrido severas transformações. Por exemplo, processo de desqualificação, desprofissionalização, intensificação do trabalho, flexibilização dos contratos, entre outros. Desse modo, todo o movimento referido tem contribuído para o definhamento da saúde dos trabalhadores da área, principalmente no que pese à saúde mental (ABONÍZIO, 2012, p. 23).

Não há como negar que os docentes da rede pública de ensino enfrentam condições de trabalho muito precárias. No editorial da revista Estudos e Pesquisas em Psicologia, que traz em sua pauta o trabalho docente, Ewald et al. (2006) apontam alguns fatores relacionados diretamente à precarização do trabalho desses profissionais da educação. As autoras iniciam sua exposição destacando a exaustiva jornada de trabalho dos professores. Muitos docentes necessitam trabalhar 40 ou 60 horas semanais para arcar com suas despesas e, por conseguinte, essa expressiva quantidade de horas trabalhadas irá interferir em sua vida pessoal e social, em seu estado de saúde geral e mental. Corroborando estes apontamentos, Forattini e Lucena (2015, 2015, p. 39-40) apontam:

A falta de reconhecimento, a desvalorização e a perda do significado social leva o trabalhador a um estado de angústia e frustração e, consequentemente, ao adoecimento. A carga de trabalho em uma profissão [...] deve ser compreendida sob dois aspectos: a carga física suportada pelo corpo e a carga

\footnotetext{
1“[...] um aglomerado de grupos empresariais com representantes e patrocínio de entidades como o Grupo Pão de Açúcar, Fundação Itaú-Social, Fundação Bradesco, Instituto Gerdau, Grupo Gerdau, Fundação Roberto Marinho, Fundação Educar-Dpaschoal, Instituto Itaú Cultural, Faça Parte-Instituto Brasil Voluntário, Instituto Ayrton Sena, Cia. Suzano, Banco ABN-real, Banco Santander, Instituto Ethos, entre outros” (SAVIANI, 2007, p. 1243).
} 
mental que o autor propõe separar em um referencial específico os elementos afetivos e relacionais ao qual chamou de "carga psíquica do trabalho".

Esses autores salientam que a saúde do profissional docente fica comprometida diante da carga excessiva de trabalho a que são submetidos. Este é apenas mais um dos desdobramentos do capitalismo, em que o trabalhador não presta seu serviço apenas para atender às suas necessidades, mas precisa fornecer trabalho excedente, o que torna sua tarefa ainda mais degradante, inclusive na área educacional.

Outro fator associado à precarização do trabalho docente, mencionado também no editorial da Estudos e Pesquisas em Psicologia (2006), é a extrapolação demasiada à sua área de formação. Ou seja, em algumas situações, o professor se vê obrigado a exercer funções para as quais não tem formação e capacitação profissional. Em muitas situações, erroneamente, são levados a cumprir o trabalho do assistente social, do psicólogo, do psicopedagogo, do enfermeiro, etc. Isso porque, em sua rotina, o sistema educacional não oferece serviços adequados e equipe especializada ${ }^{2}$ e ainda cobra do professor eficiência e resultados positivos. Forattini e Lucena (2015), sobre esta questão, posicionam-se:

A pressão pelos resultados, muitas vezes camuflada sob o véu da flexibilização e autonomia do trabalho; [...] as competências didática, administrativa, comunicacional e intelectual além da geração de ciências, formam um conjunto de exigências desgastantes, levando o docente a um estado de esgotamento das forças mentais e físicas (FORATTINI; LUCENA, 2015, p. 37).

Também está relacionada à precarização das condições de trabalho docente a falta de estrutura física ou funcional das instituições escolares. Salas de aula superlotadas, mal arejadas ou ventiladas; poucos banheiros para uso ou em condições inapropriadas se consideradas as condições estruturais e de higiene; escassez de bibliotecas, laboratórios de informática, de biologia, química e física; etc. De acordo com Dejours (1992), as condições e organizações do trabalho trazem repercussões significativas sobre a saúde do trabalhador. As condições de trabalho, que envolvem as condições físicas, químicas e biológicas do ambiente refletem-se nas condições físicas do trabalhador, já as que dizem respeito à divisão técnica e social do trabalho, como a hierarquia, controle e ritmo gerencial, trazem repercussão sobre sua saúde psíquica, provocando sofrimento, doenças físicas e mentais.

No contexto da precarização destacam-se, ainda, de forma significativa, a má remuneração, a falta do cumprimento do plano de cargos e carreiras desses profissionais, bem como a ausência de estratégias claras de efetivação das políticas de formação que permitam

\footnotetext{
${ }^{2}$ Atendimento e acompanhamento psicológico, médico ou psiquiátrico.
} 
"aos professores estar sempre ampliando as suas possibilidades de enfrentamento dos diversos problemas inerentes à ação de ensinar" (NUNES; OLIVEIRA, 2017, p.76). O descaso e a desvalorização percebidos pelos docentes nestas áreas causam desmotivação aos professores e, consequentemente, afetam sua saúde emocional.

Mancebo et al. (2006) ressaltam, também, que existem aqueles professores que ministram mais de um componente curricular e que exercem cargos e funções administrativos paralelamente à sala de aula, sobrecarregando seu trabalho. Novas demandas são somadas ao trabalho que os professores já desenvolviam. Existe ainda a realização de diversos procedimentos burocráticos, a desregulamentação da legislação trabalhista, o aumento dos contratos temporários, a falta de segurança, a violência, transferências involuntárias, falta de perspectiva com relação à carreira e preparo inadequado que fazem parte do quadro de precarização do trabalho docente (Mancebo et al., 2006).

Nesse contexto, fica evidenciado que a precarização do trabalho docente faz parte de um projeto amplo de sociedade que privilegia o desenvolvimento econômico em detrimento de melhores condições de vida e trabalho para os cidadãos e, neste caso em especial, para os professores. A desvalorização, a desapropriação e a desqualificação do trabalho docente, a cada dia, intensificam-se, dadas as investidas neoliberais que se manifestam em ações do Estado. Um exemplo disso é a Proposta de Emenda Constitucional (PEC) 241, na Câmara dos Deputados, e PEC 55, no Senado Federal, que resultou na Emenda Constitucional 95, a PEC do Teto dos Gastos (BRASIL, 2016), que congelou os gastos com os serviços públicos, inclusive com a educação, por 20 anos.

Em decorrência destes fatores, o número de docentes que tem enfrentado problemas de saúde aumentou consideravelmente. A Síndrome de Burnout é uma patologia que vem se destacando nessa conjuntura. Esta Síndrome vem sendo considerada uma questão de saúde pública, tendo em vista suas implicações para a saúde física e mental do trabalhador, com evidente comprometimento de sua qualidade de vida no trabalho. O fenômeno Burnout tem como principais sinônimos os termos esgotamento, estafa e caracteriza-se por uma multiplicidade de causas, definições e sintomas que dificultam sua delimitação e reconhecimento na comunidade científica (CODO, 1999). É prioritariamente associada ao mundo do trabalho e tem como principais características o esgotamento físico e mental e o estado de apatia, relacionado ao exercício laboral (PIMENTEL, 2015). Nessa perspectiva, Codo e Vasques-Menezes (2002, p. 254) conceituam-na como: 
abandonar o trabalho, apesar de continuar no posto. Está presente na sala de aula, mas passa a considerar cada aula, cada aluno, cada semestre, como números que vão se somando em uma folha em branco.

Além da Síndrome de Burnout, são comuns também outros transtornos psiquiátricos, como ansiedade e depressão, doenças respiratórias, problemas osteomusculares, dentre outras, que são provocadas pelas condições precárias de trabalho, as quais impedem que o professor desempenhe seu trabalho com qualidade e que tenha sua saúde assegurada.

A precarização do trabalho docente é um fato real e traz prejuízos não só para o trabalho em si, mas também para vida social, afetiva e, por conseguinte, para a saúde mental do profissional. Tal fenômeno deve ser visto de forma transdisciplinar. Sampaio (1998) nos esclarece que é preciso compreender que a saúde e o adoecimento mental não se constituem fenômenos isolados em si mesmos, eles estão intimamente vinculados.

Há que se considerar, neste contexto, todo um conjunto de demandas, as condições e a precariedade do trabalho docente, além de suas exigências e responsabilidades. Acrescente-se a isso, a atenção que o nível de trabalho exige, as cargas afetiva e emocional inclusas, a necessidade de estar e manter-se sempre atualizado com relação a seus alunos e obrigações escolares. Tudo isso se configura como uma grande pressão/tensão mental que, caso não seja trabalhada/cuidada devidamente, poderá levar esse professor ao desequilíbrio de suas emoções e comportamentos, alterações em seu estado mental/psicológico e, consequentemente, comprometer o desenvolvimento de seu trabalho e a qualidade do ensino.

Faz-se necessária e urgente a criação de espaços para discussões sobre a saúde e o adoecimento mental dos docentes (VIEIRA, 2016). Considerando a importância da saúde mental dos professores, a escassez ou ausência de serviços especializados que acolham os docentes acometidos pelo adoecimento mental, surgem-nos alguns questionamentos: Se esse professor estiver doente mentalmente, como ele desenvolverá um trabalho de qualidade? Como terá disposição e motivação para continuar a desenvolver as atribuições e exigências de sua profissão e não ter sua carreira profissional prejudicada? Como pensar em desenvolvimento educacional se a meta tem sido cortar verbas e exigir eficiência de um determinado profissional, sem levar em conta os demais fatores determinantes?

Saviani (2007) também chama atenção para relação entre a formação e as condições de trabalho docente, apontando:

Enfim, cabe insistir na íntima relação entre formação e trabalho docente deixando claro que a questão da formação de professores não pode ser dissociada do problema das condições de trabalho que envolve a carreira do magistério em cujo âmbito devem ser equacionadas as questões de salário e da jornada de trabalho. Com efeito, as condições precárias de trabalho não apenas neutralizam a ação dos professores, mesmo que fossem bem formados. 
[...]. Ora, tanto para se garantir uma formação consistente como para se assegurar condições adequadas de trabalho faz-se necessário prover os recursos financeiros correspondentes. Aí está, portanto, o grande desafio a ser enfrentado. É preciso acabar com a duplicidade pela qual, ao mesmo tempo em que se proclamam aos quatro ventos as virtudes da educação exaltando sua importância decisiva num tipo de sociedade como esta em que vivemos, classificada como "sociedade do conhecimento", as políticas predominantes se pautam sempre pela busca da redução de custos, cortando investimentos. Faz-se necessário ajustar as decisões políticas ao discurso imperante (SAVIANI, 2007, p. 75).

Refletir sobre a necessidade de oferecer condições apropriadas de trabalho por parte do Estado aos docentes torna-se essencial, frente à realidade e os desafios inerentes à docência na contemporaneidade.

\section{CONSIDERAÇÕES FINAIS}

Como exposto, o trabalho docente é complexo e repleto de especificidades. Exige atenção, domínio de assuntos e disciplinas específicas ou gerais, metodologia de ensino, práticas pedagógicas etc. Sua carga horária de trabalho é extensa e exaustiva. Estes profissionais trabalham dentro e fora da sala de aula com o desenvolvimento de atividades extraclasse. Em certa medida, não há uma estrutura física e funcional adequada nas escolas, bem como se registra má renumeração presente nesse contexto de trabalho. A docência trata-se de uma atividade laboral que envolve aspectos físicos e mentais/psicológicos, além dos fatores sociais, políticos e culturais presentes.

Mudanças têm ocorrido no mundo do trabalho em decorrência da ideologia neoliberal que vem mostrando sua força através de reformas educacionais, que primam pela privatização, pela eficiência, pelo controle e gerência da atividade docente e pela parceria entre os reformadores empresariais da educação e o Governo essencialmente neoliberal vigente. Em decorrência disto, os professores são expostos a condições de trabalho ainda mais precárias, tornando o cotidiano desse profissional, uma rotina difícil de administrar (física e emocionalmente) e vivenciar.

A sobrecarga de trabalho, o controle e o monitoramento com relação às tarefas desenvolvidas pelos professores (exercido pela parceria entre instituições públicas e privadas), as péssimas condições de trabalho, a precarização, os salários defasados e indignos, o descumprimento (não materialização) de políticas públicas voltadas para a formação e condições de trabalho e saúde são elementos que têm conduzido os professores a um sentimento de frustração e desvalorização. Nesse sentido, estes profissionais se sentem em lugar de desqualificação dentro da conjuntura do funcionalismo do poder público e/ou dentro do sistema 
MOURA, J. S.; RIBEIRO, J. C.; CASTRO NETA, A. A.; NUNES, C.P.

educacional. Do mesmo modo, a própria sociedade não se posiciona em defesa da categoria profissional responsável pela educação das gerações.

Tudo isso, certamente, influenciará a saúde e o adoecimento mental desses profissionais. É preciso compreender que a saúde do professor, seu estado emocional/psicológico/mental interfere na qualidade do ensino e da educação. Se a saúde mental do docente estiver comprometida ou se o seu estado emocional/psicológico estiver alterado, desequilibrado, o seu trabalho será diretamente influenciado.

O acometimento de doenças ou síndromes desses profissionais demonstra uma certa negligência e descaso com a saúde mental dos professores. A sociedade, o próprio meio escolar e todo o sistema apresentam dificuldades para entender a abrangência dos prejuízos do adoecimento mental dessa classe trabalhadora. A sociedade em geral precisa reconhecer a importância do trabalho docente e toda sua complexidade, assim como ter a clareza que é através do contato do sujeito com o meio escolar e com o trabalho do professor que acontece a emancipação humana. Por intermédio do trabalho desse profissional da educação, os sujeitos adquirem e aperfeiçoam capacidades cognitivas e intelectuais e aprendem a refletir criticamente.

Para romper com essa situação, torna-se necessário que a realidade atual seja transformada em prol da classe trabalhadora. Os professores precisam ser reconhecidos e valorizados pelo sistema educacional e também pela sociedade em geral. Muitas mudanças com relação às condições de trabalho e de saúde docentes precisam ser amplamente discutidas e efetivadas.

\section{REFERÊNCIAS}

ABONÍZIO, Gustavo. Precarização do trabalho docente: apontamentos a partir de uma análise bibliográfica. Revista Eletrônica Lenpes - PIBID de Ciências Sociais- Edição, nº 1, vol. 1, jan./jun. 2012.

ANTUNES, Ricardo. Os sentidos do trabalho. São Paulo: Boitempo, 1999.

BARROS, Antonilda Vasconcelos de. Trabalho docente na educação básica na rede municipal de ensino em Belém. 102 f. Dissertação (Mestrado em Educação) - Universidade Federal do Pará, Belém, 2013.

BRASIL. Emenda Constitucional $n^{o} 95$ de 15 de dezembro de 2016. Brasília, dezembro, 2016. Disponível em:

http://legis.senado.leg.br/legislacao/ListaTextoSigen.action?norma=540698\&id=14374770\&i

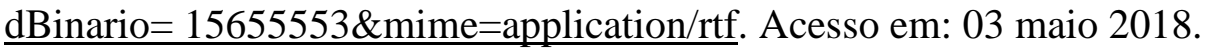

CHEPTULIN, Alexandre. A dialética materialista: categorias e leis da dialética. Tradução Leda Rita Cintra Ferraz. São Paulo: Editora Alfa-Ômega, Série 1, vol., 02, 2004. 
CODO, Wanderley (Coord.). Educação: carinho e trabalho. Petrópolis: Vozes, 1999.

CODO, Wanderley; VASQUES-MENEZES, Ione. O que é Burnout? In: CODO, Wanderley (Coord.). Educação: carinho e trabalho. Petrópolis: Vozes / Brasília: CNTE/, 2002. p.237254.

DEJOURS, Christophe. A loucura do trabalho. São Paulo: Oboré, 1992.

FERRETI, Celso João; SILVA, Monica Ribeiro da. Reforma do Ensino Médio no contexto da Medida Provisória n ${ }^{\circ}$ 746/2016: Estado, currículo e disputas por hegemonia. Educação \& Sociedade, Campinas, v. 38, nº 139, p.385-404, abr.-jun., 2017.

FORATTINI, Cristina Damm; LUCENA, Carlos. Adoecimento e sofrimento docente na perspectiva da precarização do trabalho. Laplage em Revista, vol.1, n.2, mai.-ago. 2015, p.3247.

FREITAS, Luiz Carlos. Os reformadores empresariais da educação e a disputa pelo controle do processo pedagógico na escola. Educação \& Sociedade, Campinas/SP, v.35, n. 129, p. 1085-1114, out.- dez. 2014.

FREITAS, Luiz Carlos. Os reformadores empresariais da educação: da desmoralização do magistério à destruição do sistema público de educação. Educação \& Sociedade, Campinas, v. 33, n. 119, p. 379-404, abr./jun. 2012.

GAMBOA, Silvio. A dialética na pesquisa em educação: elementos de contexto. In FAZENDA, Ivani (Org.). Metodologia da pesquisa educacional. 12. ed. São Paulo: Cortez, 2010.

GASPARINE, Sandra Maria; BARRETO, Sandhi Maria; ASSUNÇÃO, Ada Ávila. O professor, as condições de trabalho e os efeitos sobre sua saúde. Educação e Pesquisa. São Paulo, v.31, n. 2, p. 189-199, maio/ago. 2005.

GOMES, Marcos Antônio de Oliveira; COLARES, Anselmo Alencar; COLARES, Maria Lília I.; BRASILEIRO, Tânia Suely A. As mutações no mundo do trabalho na era da mundialização do capital e a precarização do trabalho docente. Revista HISTEDBR On-line, Campinas, n.47, p. 267-283, set. 2012.

KOSIK, Karel. Dialética do concreto. 7. ed. Rio de Janeiro: Paz e Terra, 1997.

MANCEBO, Deise ; EWALD, Ariane ; PRESTRELO, Eleonora Torres; UZIEL, Ana Paula. Em discussão: o trabalho docente. Editorial. Revista Estudos e Pesquisas em Psicologia. Rio de Janeiro/RJ, ano 6, n.1, $1^{\circ}$ sem. de 2006.

MARTINS, Lígia Márcia; DUARTE, Newton. Formação de professores: limites contemporâneos e alternativas necessárias. São Paulo: Editora UNESP, 2010.

MARX, Karl; ENGELS, Friedrich. O manifesto comunista. São Paulo. Cortez, 1998.

MAUÉS, Olgaíses Cabral. Educação superior e o trabalho docente no contexto da crise do capital. In: CONGRESSO IBERO-LUSO-BRASILEIRO, 2010. Anais... Portugal e Espanha: 
Anpae, 2010. Disponível em: http://www.anpae.org.br/iberolusobrasileiro2010/cdrom/95.pdf. Acesso em: 10 out. 2018.

MONTORO, Xabier. Capitalismo y Economía Mundial: bases teóricas y análisis empírico para la comprensión de los problemas económicos del siglo XXI. Madrid: Instituto Marxista de Economia, 2014.

NUNES, Cláudio Pinto; OLIVEIRA, Dalila Andrade. Trabalho, carreira, desenvolvimento docente e mudança na prática educativa. Educação e Pesquisa, São Paulo, v.43, n. 1, p. 6580, jan./mar. 2017.

OLIVEIRA, Dalila Andrade. A reestruturação do trabalho docente: precarização e flexibilização. Educação e Sociedade, v. 25, nº 89, 2004.

PEREIRA JUNIOR, Edmilson Antonio. Condições de trabalho docente nas escolas de educação básica no Brasil: uma análise quantitativa. Tese. (Doutorado em Educação) Faculdade de Educação, UFMG, Belo Horizonte, 2017.

PERONI, Vera Maria Vidal; CAETANO, Maria Raquel; LIMA, Paula Valim. Reformas educacionais de hoje: as implicações para a democracia. Retratos da Escola. Brasília. v. 11, n.21, p. 415-432, jul./dez. 2017. Disponível em: http://www.esforce.org.br. Acesso em: 5 maio 2018 .

PIMENTEL, Fernando Hugo Portela. Afinal, o que é Burnout? Tese. (Doutorado em Psicologia) - Universidade de Fortaleza, UNIFOR. Fortaleza, 2015.

SAMPAIO, José Jackson Coelho. Epidemiologia da imprecisão: processo saúde/doença mental como objeto da epidemiologia. Rio de Janeiro: FIOCRUZ, 1998.

SANTOS, Vanice dos; CANDELORO, Rosana Trabalhos acadêmicos: uma orientação para a pesquisa e normas técnicas. Porto Alegre/RS: AGE Ltda., 2006.

SAVIANI, Dermeval. A nova lei da educação: trajetória, limites e perspectivas. 8. ed. Campinas/SP: Autores Associados, 2003.

SAVIANI, Dermeval, O plano de desenvolvimento da educação: análise do projeto do MEC. Educação \& Sociedade, Campinas/SP, v. 28, n. 100 - Especial, p. 1231-1255, out. 2007. Disponível em: http://www.cedes.unicamp.br. Acesso em: out. 2018.

SAVIANI, Dermeval. Formação e condições de trabalho docente. In: Educação e Cidadania. Campinas: Alínea, 2007.

SAVIANI, Dermeval. A pedagogia no Brasil: história e teoria. Campinas, SP: Autores Associados, 2008. (Coleção Memória da Educação).

TARDIF, Maurice; LESSARD, Claude. O trabalho docente: elementos para uma teoria da docência como profissão de interações humanas. Tradução de João Batista Kreuch. 9. ed. Petrópolis: Vozes, 2014.

VIEIRA, Juçara Dutra. Direito à educação e valorização profissional: o papel do estado e da sociedade. Retratos da Escola. Brasília/DF, v. 10, n. 18, p. 25-35, jan./jun. 2016. Disponível em: http:www.esforce.org.br. Acesso em: out. 2018. 


\section{SOBRE OS AUTORES}

Juliana da Silva Moura é mestranda em Educação pelo PPGED/UESB, Pós-graduada em Psicologia Hospitalar pelo Centro Universitário de Volta Redonda-RJ (UNIFOA), graduada em Psicologia pela Universidade Federal de Alagoas (UFAL). Membro do Grupo de Estudos e Pesquisa Didática, Formação e Trabalho Docente (DIFORT/UESB) e do Centro de Pesquisa e Estudos Pedagógicos (CEPEP/UESB); Psicóloga da rede pública municipal de Itapetinga-BA.

E-mail: julymourapsi@hotmail.com

Júlia Cecília de Oliveira Alves Ribeiro é mestranda em Educação pelo PPGED/UESB, Pós-graduada em Psicopedagogia Institucional, pela Faculdade de Tecnologia e Ciências (FTC), graduada em Pedagogia pela Universidade Estadual do Sudoeste da Bahia (UESB). Membro do Grupo de Estudos e Pesquisa Didática, Formação e Trabalho Docente (DIFORT/UESB); Professora da rede pública municipal de Dário Meira-BA.

E-mail: juliaailicec@hotmail.com

Abília Ana de Castro Neta é mestranda em Educação pelo PPGED/UESB, graduada em Educação Física pela Universidade do Estado da Bahia (UNEB Campus XII). Membro do Grupo de Estudos e Pesquisa Didática, Formação e Trabalho Docente (DIFORT/UESB) e do Grupo de Pesquisa em Educação Física, Esporte e Lazer (AGENTE/UNEB).

E-mail: bia.gbi@hotmail.com

Claudio Pinto Nunes é doutor em Educação, pela Universidade Federal do Rio Grande do Norte (UFRN), pós-doutor em Educação, pela Universidade Federal de Minhas Gerais (UFMG). É membro do corpo docente do Programa de Pós-Graduação em Educação do Departamento de Filosofia e Ciências Humanas da Universidade Estadual do Sudoeste da Bahia (UESB).

E-mail: claudionunesba@ hotmail.com 